\title{
CROSS-SECTOR MANAGEMENT OF EXTREME HEAT RISKS IN ARIZONA
}

\author{
Haven E. Guyer, Hana F. Putnam, Matthew Roach, Paul Iñiguez, and David M. Hondula
}

$E^{x}$ xtreme heat has significant direct and indirect impacts on a wide array of sectors. Among the most visible indicators that extreme heat demands additional attention is its persistence as a leading cause of weather-related deaths and injuries in the United States (Berko et al. 2014). Projections of a warmer future, especially in cities, have led some researchers to identify heat as a significant threat to health and well-being for the future (Hondula et al. 2015). In Arizona, public leaders are taking a proactive approach to build collaboration to address one of the state's most consequential natural hazards. Exposure to excessive natural heat in the state caused 1,193 deaths from 2006 to 2016 (ADHS 2016).

The second Annual Arizona Extreme Heat Planning Workshop in the spring of 2018 convened representatives from organizations and departments who are on the front lines of addressing extreme heat statewide. The concept of a broadly inclusive

AFFiliations: GuYer, PUTNAM, AND HONDULA-School of Geographical Sciences and Urban Planning, Arizona State University, Tempe, Arizona; ROACH-Arizona Department of Health Services, Phoenix, Arizona; INIIGUEZ-Phoenix Weather Forecast Office, National Weather Service, Phoenix, Arizona CORRESPONDING AUTHOR: David M. Hondula,

david.hondula@asu.edu

DOI:I0.II75/BAMS-D-18-0183.|

In final form 10 July 2018

(C)2019 American Meteorological Society

For information regarding reuse of this content and general copyright information, consult the AMS Copyright Policy.

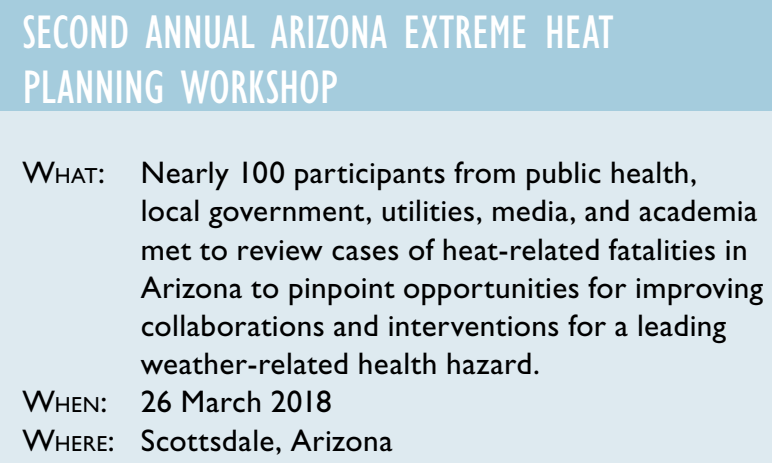

WHAT: Nearly 100 participants from public health, local government, utilities, media, and academia met to review cases of heat-related fatalities in Arizona to pinpoint opportunities for improving collaborations and interventions for a leading weather-related health hazard.

WHEN: 26 March 2018

WHERE: Scottsdale, Arizona

annual heat planning workshop was developed from a working group spearheaded by the Arizona Department of Health Services (ADHS). ADHS had been organizing a heat-health working group after receiving funding from the Centers for Disease Control and Prevention's Climate-Ready Cities and States Initiative. With collaborators such as the National Weather Service (NWS), Arizona State University (ASU), and The University of Arizona, the working group conceived of expanding planning efforts to include a greater number of stakeholders across sectors beyond public health. The group recognized that prevention and response efforts could be improved by collaborating with nontraditional public health partners and by addressing the perception among the heat community that efforts to plan for extreme heat were siloed, leading to inefficiencies. Through a large and inclusive in-person annual meeting, the group aimed to increase communication and connectivity among heat stakeholders. 
WORKSHOP STRUCTURE AND PARTICIPANT PROFILE. The workshop was structured to illuminate barriers to ensuring that Arizonans are safe during the summer heat. This theme was developed based on input received at the inaugural statewide heat workshop in 2017, where participants consistently identified a reduction in heat-related deaths as a suitable indicator for community success in heat preparedness and response. Based on this feedback, the workshop organizers designed the 2018 program to focus the conversation more directly on heat-related deaths and their relevance to indicating success, as opposed to thermal comfort, urban heat mitigation, or other heat-related issues.

Participation increased in the number of individuals and sectors represented in comparison with the previous year. In 2018, nearly 100 participants registered, representing approximately 40 different organizations. Many participants identified themselves as part of the research, public health, utility, emergency management, local government, or nonprofit sectors. The 2018 workshop had increased participation from the media sector, which organizers and participants had identified as a goal the previous year.

The 2018 workshop began with brief presentations by representatives from ADHS, the City of Phoenix, and NWS, who all shared perspectives on the previous season's heat, its health impacts, and municipal response. These presentations provided the framing for the majority of the meeting, which involved small group discussions. The discussions centered on a series of articles authored by the Arizona Republic in 2017 titled "The Human Cost of

\section{TABLE I. Questions provided to each facilitator for small group semistruc-} tured discussion.

\section{Facilitator questions}

What actions could have prevented this death from occurring, and others like it? Of the people at this table, who could have taken those actions?

If you interacted with this case, what role(s) would you or your organization have taken, if any?

What are the opportunities to collaborate around the actions we are proposing?

If we took the actions that we are discussing, how many other people would benefit? Would those actions extend beyond preventing heat-related deaths to preventing heat-related illnesses? Improvements in quality of life? Other benefits?

Is this case one that people at this table feel capable of addressing? If not, why?

What are the organizations best positioned to take action for this case?

Which organizations should collaborate with first responders in responding to this type of event?

How could we improve educational campaigns and messaging to prevent this type of situation from occurring?
Heat." In advance of the workshop, newspaper staff granted permission to the workshop organizers to use their content. The articles were individual narratives of the circumstances under which 30 people of diverse ages, socioeconomic statuses, health conditions, and family arrangements tragically lost their lives due to extreme heat exposure (Arizona Republic 2017). Each four-six-person group received an article that detailed the conditions surrounding one specific fatality. After reviewing their assigned story, participants brainstormed and discussed what actions could have reduced the risk of heat ilness or death for their specific case. A facilitator at each group used prepared questions as prompts could prevent similar outcomes, and which organizations and sectors are best suited to implement

FINDINGS. Risk factors/barriers to safety. The risk factors identified by participants did not differ dramatically from those commonly supported by heat-health literature (e.g., CDC 2017). Risk factors that participants identified included preexisting respiratory or cardiovascular health conditions, mental illness, homelessness, low access to certain social services, low access to air conditioning, social isolation, living in a trailer, limited knowledge of avallable resources, outdoor occupation, and low risk perception of the impact heat can have on health. dividual cases provided gave stakeholders a more nuanced understanding of the occasionally complex conditions and pathways from which heat deaths result in addition to an opportunity to consider how their organizations might map onto the response. One participant from NWS noted that understanding the context around the deaths was important: "all [are] heat deaths but [there are] many underlying causes... makes it difficult to figure out ways to address it." Participants also noted that the narratives increased the relatability of heat-health 
risks because they illustrated specific links between risk factors and outcomes.

Potential actions. The context provided by the cases helped participants identify a number of strategies that are consistent with those widely recommended by public health agencies and weather services, but also catalyzed discussion about interventions and solutions that were novel. For example, one group's recommendations centered around informing hikers about the danger of physical activity on extremely hot days. Their idea was to post statistics at trailheads, which could give recreationalists information on how many people are rescued from the trail. They also suggested giving different trails heat-danger ratings similar to those given to skiing trails (e.g., a black diamond ski path is not meant for beginners, similarly, a "red heat level" trail should only be undertaken when the temperature is relatively low).

Other groups discussed new ways to connect people in need to community support programs and resources. Air conditioning was a priority concern, especially in light of health statistics that suggest upward of half of the cases of heat-associated deaths in the Phoenix area are related to exposure indoors (MCDPH 2017). One group suggested creating an air conditioning response team with a specific response protocol that could include air conditioning repairs, connection to relevant social services, and reporting the visit to a local health department. Another group discussed the possibility of utility companies collaborating with a local community college to perform air conditioning repairs free of charge. This approach would provide students with practical experience while addressing the risk faced by low-income people who do not have the financial resources to fix their air conditioner. Participants identified emergency departments (EDs) as a potential site for activating longer-term interventions and response for people with heat-related illness. If someone presented with heat illness at the ED, a host of actions, such as connecting them with necessary social services, could be taken to help reduce the probability that they return to the ED or face more critical consequences.

Heat governance. Consistent with previous research, workshop participants had differing ideas on who bears the responsibility for preparing for and responding to extreme heat (Mees et al. 2015). After generating ideas about the types of interventions that may have been effective for certain cases, groups were challenged to identify organizations and sectors that would be best positioned to take a lead role in deploying or coordinating those interventions. Participants voiced a wide range of ideas about how to govern heat and its health risks. Communities, nonprofits, and faith-based and grassroots organizations were mentioned as groups that could take on greater efforts to ensure people are hydrated and safe. Some participants felt that these groups would be most appropriate to lead these efforts, as they may be more knowledgeable and trusted in the community than government agencies or private corporations. In contrast, another group felt that leadership from private utility companies was necessary given the important role they play in providing refuge from the heat. Others suggested that state and local emergency management (EM) should take a more prominent role in preparing communities for heat. However, participants from the EM sector were uncertain of how heat preparedness and response aligns with their current responsibilities. Some EM professionals even perceived that heat was outside of their scope of work.

Discussions about who should lead, manage, and deliver services related to heat preparedness and response highlight the importance of coordination across many sectors. Workshop organizers and participants alike noted that there were few attendees with the capacity to make formal policy decisions. Consequently, discussions mostly focused on programmatic, short-term actions, rather than large-scale, systematic, policy-supported changes. As one participant stated in the exit survey, "there needs to be...more systems level approaches to solutions." Although the purpose of the workshop was not to designate a specific governance structure and responsibilities for future heat mitigation and adaptation, the uncertainty among participants about the realm of possibilities at a policy level likely stymied some creative conversation. Participants also noted that faith-based organizations; schools and educators; and heating, ventilating, and air-conditioning (HVAC) companies were not adequately represented at the meeting. In addition to cross-sector participation, multilevel collaboration (and a stronger bridge to the policy community) will be encouraged at future meetings to enhance the breadth of strategies discussed among participants.

LOOKING AHEAD. The workshop was successful in establishing connections between individuals and agencies working to mitigate impacts from extreme heat, but gaps remain in understanding best practices for heat preparedness and response. One participant who responded to the meeting's exit survey remarked, "[the meeting] was great, we are making changes 
in our organization now because of it." Workshop organizers found that attendees each met three or four new potential collaborators and expected to be in contact with at least two of those people during the upcoming heat season.

Addressing issues associated with heat can be difficult due to a lacking evidence base. Many current strategies have not been evaluated for efficacy, contributing to confusion about whether new solutions are needed or best practices have already been realized. Using the case studies of real people who lost their lives because of extreme heat gave participants a chance to think critically of known intervention strategies and consider who may be best suited to initiate these measures. Participants were enthusiastic about working to build a set of best practices based on their experience and sharing them with other stakeholders as they learn what works. Some of these efforts are already underway; several local health departments in Arizona are working to analyze the efficacy of current interventions (e.g., cooling centers; Berisha et al. 2017). Participants also expressed interest in a central repository of ongoing heat-relief efforts to enhance community awareness of available services and projects. A heat project database would create greater opportunities for collaboration and allow stakeholders to inform clients of available services if they are in need. Workshop organizers are now working to identify ways to build the set of best practices and share, communicate, and engage others with the information.

ACKNOWLEDGMENTS. The workshop and organizers were partially supported by the Centers for Disease Control and Prevention cooperative agreements CDC-RFA-EH16-1602: Enhancing Community Resilience by Implementing Health Adaptations (Award 5 NUE1EH001318-02-00) and CDC-RFA-EH17-1702: Enhancing Innovation and Capabilities of the Environmental Public Health Tracking Network (Award 1 NUE1EH001339-01-00). The organizers thank staff at ASU SkySong for generous logistical support, writers at the
Arizona Republic for contributions to meeting organization and facilitation, and ASU, NWS, and ADHS staff and students who served as facilitators and notetakers.

\section{REFERENCES}

ADHS, 2016: Mortality and morbidity from exposure to excessive natural heat in Arizona, 2006-2016. ADHS Rep., 30 pp., https://pub.azdhs.gov/health-stats /report/heat/heat-2016.pdf.

Arizona Republic, 2017: The human cost of heat. Accessed 15 June 2018, http://static.azcentral.com /human-cost-heat/.

Berisha, V., and Coauthors, 2017: Assessing adaptation strategies for extreme heat: A public health evaluation of cooling centers in Maricopa County, Arizona. Wea. Climate Soc., 9, 71-80, https://doi.org/10.1175 /WCAS-D-16-0033.1.

Berko, J., D. D. Ingram, S. Saha, and J. D. Parker, 2014: Deaths attributed to heat, cold, and other weather events in the United States, 2006-2010. National Health Statistics Reports 76, 16 pp., www.cdc.gov /nchs/data/nhsr/nhsr076.pdf.

CDC, 2017: Protecting vulnerable groups from extreme heat. Centers for Disease Control and Prevention, accessed 30 June 2018, www.cdc.gov/disasters /extremeheat/specificgroups.html.

Hondula, D. M., R. C. Balling, J. K. Vanos, and M. Georgescu, 2015: Rising temperatures, human health, and the role of adaptation. Curr. Climate Change Rep., 1, 144-154, https://doi.org/10.1007 /s40641-015-0016-4.

MCDPH, 2017: Heat yearly mortality reports. Maricopa County Department of Public Health, accessed 30 June 2018, www.maricopa.gov/Archive .aspx?AMID=103.

Mees, H. L., P. P. Driessen, and H. A. Runhaar, 2015: "Cool" governance of a "hot" climate issue: Public and private responsibilities for the protection of vulnerable citizens against extreme heat. Reg. Environ. Change, 15, 1065-1079, https://doi.org/10.1007 /s10113-014-0681-1. 